\title{
Humor During Clinical Practice: Analysis of Recorded Clinical Encounters
}

\author{
Kari A. Phillips, BA, Naykky Singh Ospina, MD, MS, Rene Rodriguez-Gutierrez, MD, MS, \\ Ana Castaneda-Guarderas, MD, Michael R. Gionfriddo, PharmD, PhD, \\ Megan Branda, MS, and Victor Montori, MD, MSC
}

Objective: Little is known about humor's use in clinical encounters, despite its many potential benefits. We aimed to describe humor during clinical encounters.

Design: We analyzed 112 recorded clinical encounters. Two reviewers working independently identified instances of humor, as well as information surrounding the logistics of its use.

Results: Of the 112 encounters, 66 (59\%) contained 131 instances of humor. Humor was similarly frequent in primary care $(36 / 61,59 \%)$ and in specialty care $(30 / 51,59 \%)$, was more common in gender-concordant interactions $(43 / 63,68 \%)$, and was most common during counseling $(81 / 112,62 \%)$. Patients and clinicians introduced humor similarly (63 vs 66 instances). Typically, humor was about the patient's medical condition $(40 / 131,31 \%)$.

Discussion and Conclusion: Humor is used commonly during counseling to discuss the patient's medical condition and to relate to general life events bringing warmth to the medical encounter. The timing and topic of humor and its use by all parties suggests humor plays a role in the social connection between patients and physicians and allows easier discussion of difficult topics. Further research is necessary to establish its impact on clinicians, patients, and outcomes. (J Am Board Fam Med 2018;31: 270-278.)

Keywords: Humor, Patient-Centered Care, Primary Health Care, Physician-Patient Relations, Patient-Physician Communication

Adequate and open communication between patients and clinicians can have a positive effect on the outcomes of care. ${ }^{1}$ Positive interactions between patients and physicians in the medical en-

This article was externally peer reviewed.

Submitted 21 July 2017; revised 17 November 2017; accepted 28 November 2017.

From the Mayo Clinic School of Medicine, Rochester, MN (KAP); Division of Endocrinology, Department of Medicine, University of Florida, Gainesville, FL (NSO); Knowledge and Evaluation Research Unit, Division of Endocrinology, Diabetes, Metabolism and Nutrition, Department of Medicine, Mayo Clinic, Rochester (NSO, RRG, VM); Division of Endocrinology, Department of Internal Medicine, University Hospital "Dr. Jose E. Gonzalez," Universidad Autónoma de Nuevo León, San Nicolás de los Garza, N.L., Monterrey, Mexico (RRG); National Laboratory for the Study and Application of Evidence Based Medicine, Critial Analysis of Scientific Information and Pharmacoeconomics, Universidad Autónoma de Nuevo León, San Nicolás de los Garza, N.L., Monterrey, Mexico (RRG); Department of Emergency Medicine, Aventura Hospital and Medical Center, Aventura (ACG); Center for Pharmacy Innovation and Outcomes, Geisinger Health System, Forty Fort, PA (MRG); Robert D. and Patricia E. counter helps build a relationship, establish trust, and support the exchange of accurate and relevant information, all of which may contribute to achieving favorable health outcomes. ${ }^{2}$ In fact, the Accreditation Counsel of Graduate Medical Education considers interpersonal and communication skills to be one of the core competencies to be taught to physicians in training. ${ }^{3}$ Although many strategies exist to bolster physician-patient communication, humor is particularly interesting due to its utility in

Kern Center for the Science of Health Care Delivery, Mayo Clinic, Rochester (MB); Department of Health Sciences Research, Division of Health Care Policy and Research, Mayo Clinic, Rochester (MB).

Funding: none.

Conflict of interest: none declared.

Corresponding author: Victor Montori, MD, MSc, Knowledge and Evaluation Research Unit, Division of Endocrinology, Diabetes, Metabolism and Nutrition, Mayo Clinic, 200 1st Street SW, Rochester, MN 55905 (E-mail: montori.victor@mayo.edu).

KAP and NSO contributed equally to this work. 
navigating difficult topics and potential to bridge gaps between patients and clinicians. ${ }^{4,5}$

Humor is one of many verbal and nonverbal strategies used by patients and physicians to connect in the medical encounters. In 1996 Wender $^{6}$ and in 1999 Frances and colleagues ${ }^{7}$ discussed the role of humor in clinical practice. Humor, they posited, could reduce anxiety, demonstrate connectedness, and invite warmth into an interaction that is otherwise formal, cold, and distant. Humor can be a mean for physicians to surface difficult or uncomfortable topics, subtly express dissatisfaction with the patient's behavior, provide reassurance, or get the patient's attention. In addition, it can invite patients to comfortably express anxiety or discuss frustration with their diagnosis, treatments, or with the medical system. Humor has the potential to decrease power imbalance and cultural differences between patients and physicians, which can otherwise hinder open communication. ${ }^{6,7}$ Humor has also been correlated with positive outcomes such as improved satisfaction, fewer malpractice claims, and increased patient enablement. ${ }^{8-11}$

Although humor may serve numerous beneficial functions in clinical encounters, there is no standard definition of humor for research purposes and the logistics of humor's use in clinical encounters (eg, frequency, who introduces it, what is it about) has not been well studied. Where it has been studied, its prevalence varies widely across settings (inpatient rounds, emergency department, hospice; Table 1$).{ }^{8-16}$

To further characterize the logistics of humor in medical encounters, we analyzed audio/video-recorded clinical encounters to describe the frequency and other features of humor in outpatient primary and specialty care visits.

\section{Methods}

We analyzed clinical encounters recorded as part of practice-based randomized trials conducted to examine the effect of decision aids on shared decision making (published between 2009 and 2015). ${ }^{17-23}$ Recordings were audiovisual or audio-only based on the preferences of the patients and their clinicians at the time of enrollment. Of the 272 complete videos available for analyses from these trials, we included all the videos that were recorded in specialty care (51) and selected a random sample of 61 videos from the 221 remaining primary care videos stratified by treatment arm (decision aid use) to complete a sample of 112 videos. $^{24}$

Our primary objective was to quantify and evaluate the use of humor; however, the concept of humor is subjective and lacks a standardized definition. Thus, 12 recordings were analyzed by 4 experienced independent reviewers (all with medical training) to define what constitutes an instance of humor, calibrate the coding, and identify variables to be collected. Humor was defined as a statement made with the intent to make others in the room laugh or react positively (ie, deemed humorous by reviewers) and to which a positive response was elicited. Therefore, unacknowledged humorous comments or statements that were not intended to be funny (ie, deemed not humorous by reviewers) but were laughed at nonetheless were not included (eg, nervous laughter within a generic conversation). Once calibration was achieved, 2 reviewers working independently analyzed each one of the remaining recordings. Humor was considered present when both reviewers identified the instance as humorous.

Coding was completed using Noldus $\mathrm{XT}^{25}$ software. For all videos, reviewers recorded how many physicians interviewed the patient, the gender of the patient, and senior clinician, the setting (primary care, specialty care), whether a decision aid was used, the duration of the encounter, and whether a physical examination was performed. Use of humor was coded as a binary (humor present or absent during the whole visit) and quantitative variable (how many times humor was noted in the visit). For each instance of humor within the encounter, reviewers recorded who introduced humor (patient, provider or guest), timing (introduction, history taking, physical examination, or counseling), subject, apparent function of the humor, and whether the instance was a single statement ("dead end") or resulted in a string of humorous back-and-forth comments. These data were collected using Research Electronic Data Capture (REDCap), a data collection and management program. ${ }^{26}$ Contextual clues were used by reviewers to determine the subject and function of humor, and disagreements were resolved by consensus. We compared the proportion of encounters with humor by setting, decision aid use, and participant gender. Hypotheses testing of differences between groups was performed using the $\chi^{2}$ statistic and adjusted $\chi^{2}$, where the clustering was within study. 


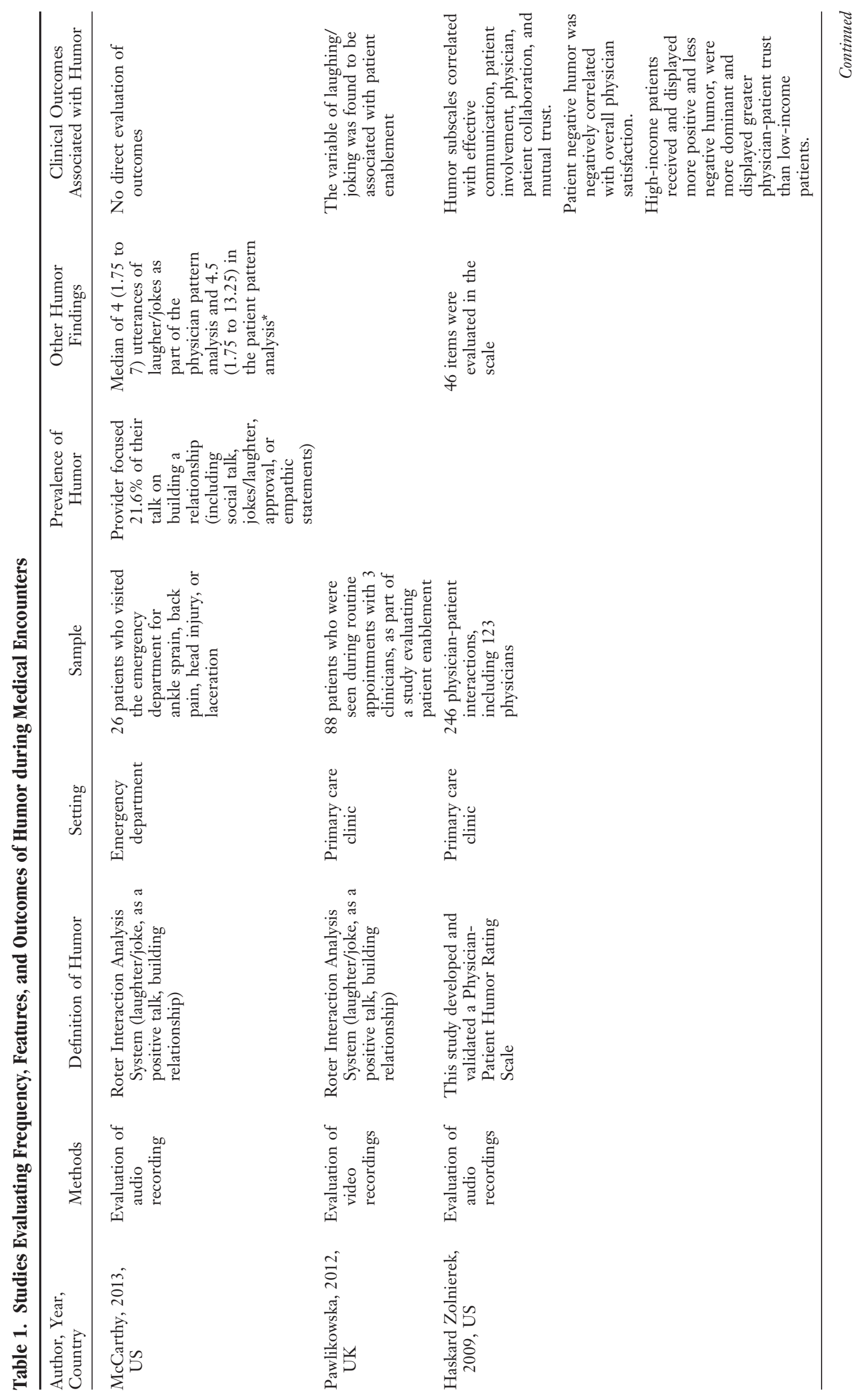




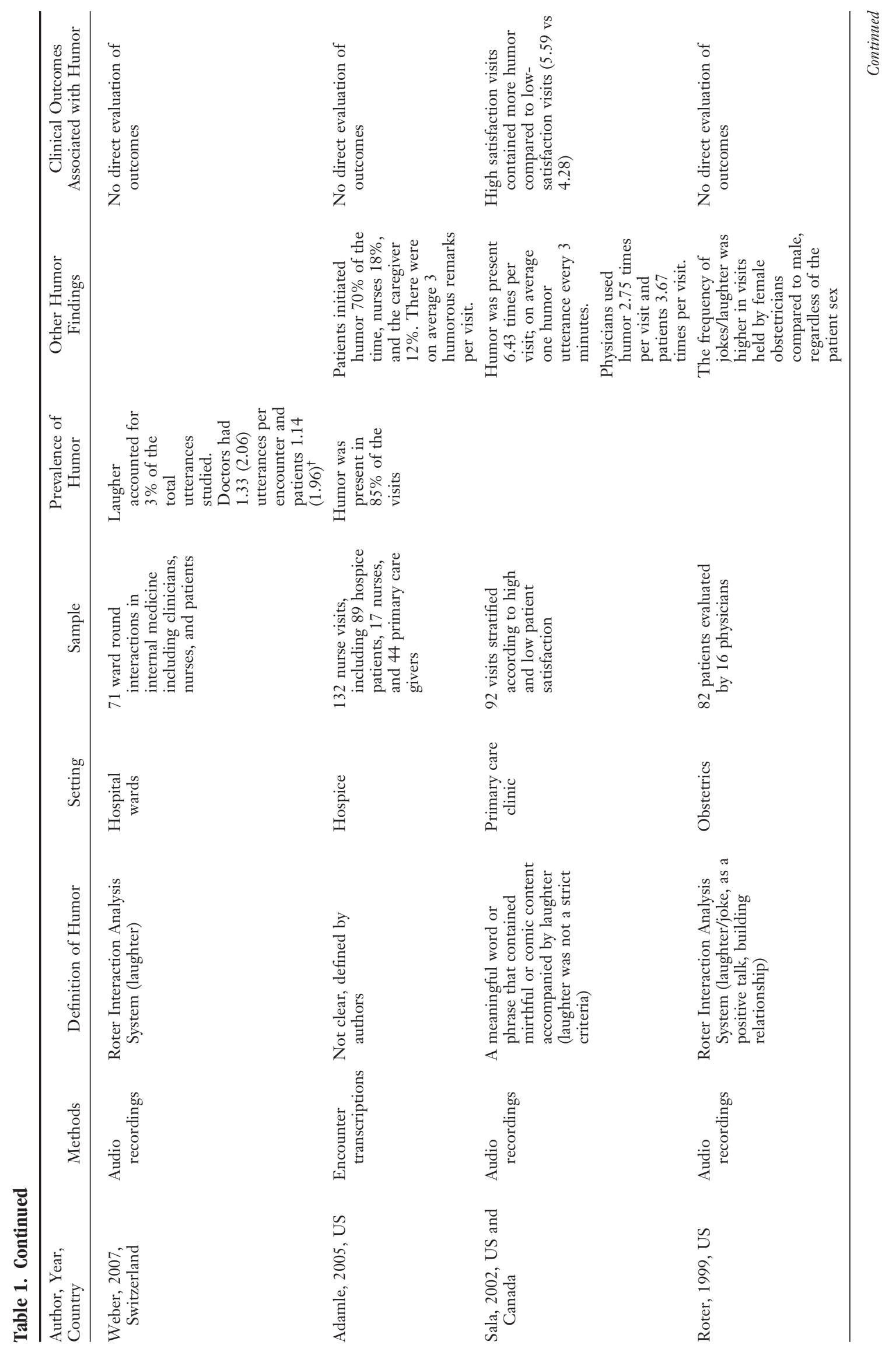

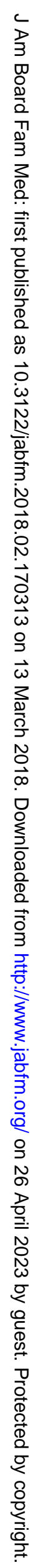




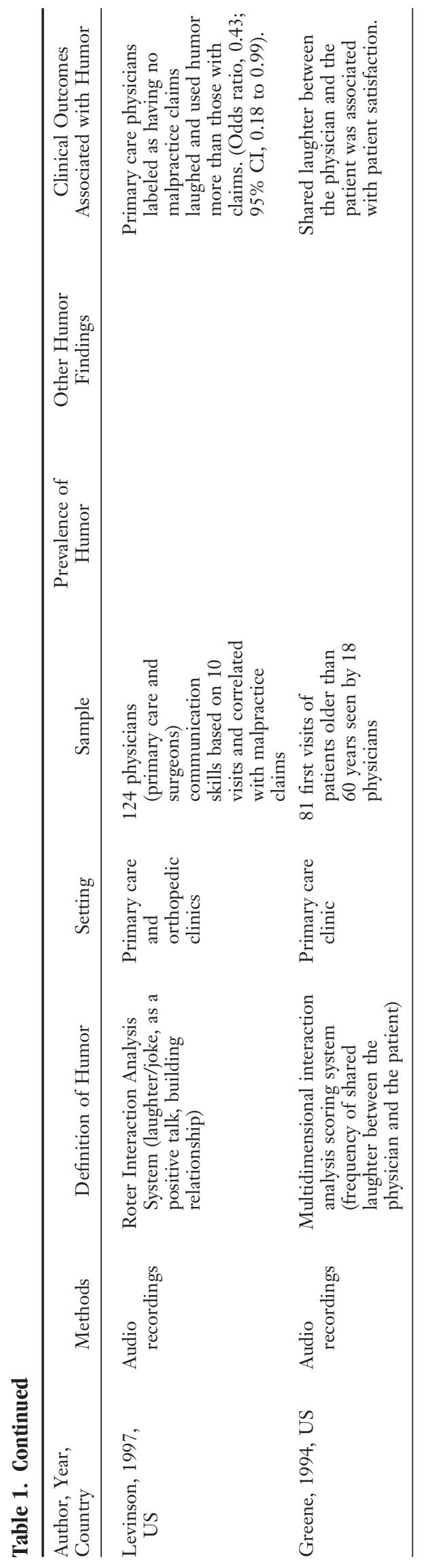

This method accounted for any intraclustering effect across studies. ${ }^{27}$ All statistical analyses were performed using $\mathrm{JMP}^{28}$ and Stata Statistical Software. $^{24}$

\section{Results}

Of the 112 medical encounters, 87 (78\%) were audiovisual recordings and $25(22 \%)$ were audio only. Most video recordings took place in primary care clinics $(61 ; 54 \%)$, with $51(46 \%)$ taking place in specialty care clinics. The median encounter duration was 30 minutes (range, 4 to 80 minutes). Humor was present in 66/112 (59\%) of these encounters. A total of 131 instances of humor were identified with a median of 2 humorous instances per humor-containing encounter (interquartile range, 1 to 2 ; range, 1 to 5 ).

Humor was similarly present regardless of participant gender, setting (primary or specialty care), and in encounters with and without shared decision-making tools. However, there was significantly more humor used when the senior clinician and patient were of the same gender (43 of 63 encounters; $68 \%$ ) than when they were not (23 of 49 encounters; $47 \% ; P=.02$; Table 2).

Humor was used most commonly during the counseling of the medical encounter $(62 \%$ of the encounters; Table 3). Representative examples of humor are presented in Table 4.

\section{Discussion}

In this study, we found that humor was present in approximately $60 \%$ of encounters at an average rate of 2 instances per encounter. Humor was most commonly used in the counseling portion of the encounter and was introduced by the patient and physician almost equally. The most common subject of humor was the patient's medical condition. The function of humor was most often to relate to general life or to discuss adherence and other difficult topics. Humor was often limited to one-line exchanges ("dead end").

There was no difference in the use of humor between primary- and specialty-care settings, nor was there a difference based on the gender of the clinician or patient or any effect from the use of a decision aid. However, when the patient and the senior clinician were of the same gender, humor was used more often. This phenomenon was noted by Roter et $\mathrm{al}^{16}$ in the obstetrics setting as well. 
Table 2. Distribution of the Use of Humor According to Setting, Decision Aid Use, and Gender of the Patient and Senior Clinician

\begin{tabular}{|c|c|c|c|}
\hline & $\begin{array}{l}\text { Humor Present } \\
\qquad(\mathrm{n}=66)\end{array}$ & $\begin{array}{l}\text { Humor Absent } \\
\quad(\mathrm{n}=46)\end{array}$ & $P$ Value \\
\hline Distribution by setting & & & .98 \\
\hline Primary care & $36 / 61,59 \%$ & $25 / 61,41 \%$ & \\
\hline Specialty clinic & $30 / 51,59 \%$ & $21 / 51,41 \%$ & \\
\hline Distribution by use of decision aid & & & .605 \\
\hline Decision aid, yes & $31 / 50,62 \%$ & $19 / 50,38 \%$ & \\
\hline Decision aid, no & $35 / 62,56 \%$ & $27 / 62,44 \%$ & \\
\hline Distribution by gender of the patient & & & .29 \\
\hline Male patient & $31 / 48(65 \%)$ & $17 / 48(35 \%)$ & \\
\hline Female patient & $35 / 64(55 \%)$ & $29 / 64(45 \%)$ & \\
\hline Distribution by sex of senior clinician & & & .84 \\
\hline Male clinician & $40 / 67(61 \%)$ & $27 / 67(40 \%)$ & \\
\hline Female clinician & $26 / 45(58 \%)$ & $19 / 45(42 \%)$ & \\
\hline Distribution by gender congruence & & & .02 \\
\hline Gender congruent & $43 / 63(68 \%)$ & $20 / 63(32 \%)$ & \\
\hline Gender incongruous & $23 / 49(47 \%)$ & $26 / 49(53 \%)$ & \\
\hline
\end{tabular}

Though a reason for this phenomenon has not been proposed or explored, we hypothesize 2 possible causes for this finding. First, it may be due to an increased level of comfort sensed between individuals of a similar gender. In addition, those of concordant gender tend to have more similar senses of humor, thus may feel more comfortable

Table 3. Proportion of Humor Use by Portion of the Encounter, by Subject and by Purpose

\begin{tabular}{lc}
\hline & $\mathrm{n} / 131, \%$ \\
\hline Humor use by portion of encounter & \\
Counseling & $81,62 \%$ \\
Data gathering & $22,17 \%$ \\
Introduction/opening & $15,11 \%$ \\
Physical exam & $13,10 \%$ \\
Humor use by subject & \\
Medical condition, treatment, testing & $40,31 \%$ \\
Patient & $29,22 \%$ \\
Third party (not present) & $18,14 \%$ \\
Physician & $16,12 \%$ \\
Other & $16,12 \%$ \\
General life & $9,7 \%$ \\
Third party (present) & $3,2 \%$ \\
Humor use by purpose & \\
Relate to general life & $44,34 \%$ \\
Other & $32,25 \%$ \\
Introduce difficult topics & $20,15 \%$ \\
\hline & $20,14 \%$ \\
Patient adherence & $15,11 \%$ \\
\hline
\end{tabular}

introducing humor into an interaction. Finally, although we did not have access to data to verify this, it is plausible that more gender-concordant pairs were those of primary-care provider and patient. The familiarity in these relationships may allow for easier use of humor.

Based on our observational findings, it is difficult to draw concrete conclusions about the benefits of humor in these encounters. However, based on the data we gathered, we can infer agreement with previously published literature regarding the uses of humor in clinical encounters (Table 1).

The counseling portion of the medical encounter is commonly when discussions of diagnosis, treatment, adherence, and other potentially difficult topics surface, thus necessitating some of the key functions of humor. Humor was most often seen in this portion of the interview, suggesting it is being used in these discussions. It is possible that humor allows patients and physicians to more openly broach these otherwise-uncomfortable topics and helps maintain a productive interaction. .,7 $^{-1}$

The fact that humor was used to relate to general life events and circumstances provides further evidence that humor can be used to promote connectedness and warmth, as previously stated by Wender and Frances. ${ }^{6,7}$ Patients and physicians experience a network of roadblocks that can ruin efforts of communication. Power imbalance, gender differences, age discrepancy, and varied cultural 
Table 4. Examples of Humor by Subject, Time, and Type

\begin{tabular}{|c|c|}
\hline \multicolumn{2}{|l|}{ By Subject } \\
\hline \multirow[t]{3}{*}{ Medical condition/treatment/testing } & $\begin{array}{l}\text { Patient: I went [to the pharmacy] one day, my medication was like } \$ 250 \text {, and I just } \\
\text { about fainted. }\end{array}$ \\
\hline & Doctor: And your liver should be normal. Do you want me to do a liver biopsy just to see? \\
\hline & $\begin{array}{l}\text { Patient: So, the first time that I was diagnosed with Graves' disease I lost about } 20 \text { pounds } \\
\text { and I was eating whatever I wanted. It was like the best weight loss diet ever! }\end{array}$ \\
\hline \multirow{8}{*}{ Patient } & Doctor: You could eat whatever you want and still lose weight, ha-ha \\
\hline & Doctor: It's well tolerated because, you know, you're just a young kid. \\
\hline & Patient: Haha oh yah \\
\hline & Doctor: Well ... sort of. Haha, you know you look great. You do! \\
\hline & Patient: Haha. Far from a young kid. Hahaha \\
\hline & It is all who you are talking to as to whether you are a young kid or not. \\
\hline & $\begin{array}{l}\text { Doctor: That is good to hear. Some people are of the mentality that they know } \\
\text { everything there is to know and do not want to meet with a dietitian. }\end{array}$ \\
\hline & Patient: Oh, no! I got kids; I have been told repeatedly that I do not know anything! \\
\hline \multirow[t]{3}{*}{ Third party (not present) } & $\begin{array}{l}\text { Patient: You know I have to chase my husband off to the doctor every now and then for } \\
\text { [skin checks]. }\end{array}$ \\
\hline & $\begin{array}{l}\text { Patient: ... My kids are so spoiled, they are so dependent on me. My son asked me the } \\
\text { other day, \&lquote;Mom where is the fork so that I can eat my dinner!' Ha ha }\end{array}$ \\
\hline & Doctor: I ask my wife that! \\
\hline \multirow[t]{3}{*}{ Physician } & Doctor: Blood pressure is $139 / 75$ [elevated] \\
\hline & Patient: Oh that must be because of you! Haha because when I used to come in ... \\
\hline & Doctor: Oh ha-ha! I am not very intimidating! \\
\hline \multirow[t]{2}{*}{ General life } & $\begin{array}{l}\text { Doctor: So, you are taking the medication for the cholesterol and at last fall, you had } \\
\text { asked about stopping it due to muscle pains. }\end{array}$ \\
\hline & $\begin{array}{l}\text { Patient: Yeah, during the winter there were a few nights that I was having leg cramps, } \\
\text { but I thought it was related to surviving the Minnesota winter! }\end{array}$ \\
\hline
\end{tabular}

\section{By portion \\ Introduction}

Patient: It's [the video recording] so funny because of YouTube

Doctor: Haha. Right. Everything is on YouTube. Ha-ha

Patient: Kids will tape it and they cannot figure out why they get in trouble if they put it on and somebody sees it.

[Both laughing]

Doctor: And that Facebook is worse because feel like 'Ohhh' you know and they can comment.

\begin{tabular}{ll}
\hline Data gathering & Doctor: Do you test [blood sugars] ever? \\
& Patient: Only when I come in here! Ha-ha \\
& Both laugh \\
\hline Physical exam & Doctor: Well I will have you sit right there and I will listen to you, ok? \\
& Patient: You can make me have that [stethoscope] and I'll talk into it. \\
& Both laugh \\
& Doctor: [holding the tuning fork] Are you into music. Watch this! [hits tuning fork so \\
that it starts buzzing] & Doctor: This is not like selling encyclopedias. This offer [medication adjustments] stays \\
& open after today! \\
\hline Counseling & Patient: I should get my [institution name] medical book out, but it's too darn heavy for \\
& me to get out because my ribs are broken. Haha \\
\hline Dead end vs continued exchange & Doctor: It's well tolerated because, you know, you're just a young kid. \\
Patient: Haha oh yah & Doctor: Well . . sort of. Haha, you know you look great. You do! \\
Patient: Haha. Far from a young kid. Hahaha \\
It is all who you are talking to as to whether you are a young kid or not.
\end{tabular}


and socioeconomic backgrounds can all lead to hindered communication. In turn, this can affect the patient experience and the efficacy of the clinical encounter. ${ }^{29,30}$ Humor may help to overcome those roadblocks by connecting people on common ground. ${ }^{7}$ As an example, it was noted that patients and physicians commonly discussed pets or spouses in humorous ways. This allowed for connection on a simple level, which could serve as a launching point for more serious and intimate conversations. An improved personal connection may explain the increased patient satisfaction noted in visits with more humor. ${ }^{11}$

Our study cannot make concrete conclusions nor suggest recommendations for medical education or clinical practice. However, it quantifies the use of humor in the clinical encounter, and it suggests agreement with previously published literature regarding the uses and benefits of humor.

In this study, we evaluated the use of humor in medical encounters. All videos were reviewed in duplicate to increase reliability. This is important when characterizing a subjective construct like humor. In seeking rigor, we may have underestimated the use of humor, as we required agreement between 2 reviewers to adjudicate an instance as humorous. A limitation of our study is that we did not confirm our judgments regarding the humorous intent of each statement with the participants nor did we obtain judgments from observers with nonmedical backgrounds. In addition, our assessment of available videos is convenient and not necessarily representative. Our medical encounters were collected within a health system with longer than average appointment times in both primary and specialty and were recorded as part of clinical trials assessing the efficacy of decision aids. Thus the data may not be widely representative.

A few studies have sought to identify and explore the impact of humor in the medical encounter, but few identify its frequency and none explore other logistic aspects of its use in clinical encounters. Our study contributes to reduce this knowledge gap. Future studies may need to apply video-reflexivity techniques to capture participant views of humor use in encounters. Additional research may need to characterize how humor use can facilitate or hinder partnership, communication, and conflict resolution and contribute to improve the experience of care for clinicians and patients and the usefulness of the encounter. Finally, while focusing on humor, we noticed in some recordings that patients or clinicians would laugh or chuckle when nothing funny was said. Often this went unacknowledged by the other party. The significance of this sign, for example, as a marker of unstated anxiety or discomfort, deserves further exploration.

\section{Conclusion}

The use of humor during medical encounters is common, occurring in about 6 of 10 encounters. It seems to be introduced equally by patients and clinicians in both primary- and specialty-care settings. Studies have demonstrated a positive impact of humor on a number of outcomes ${ }^{8-11}$. Our study serves to describe in detail how humor is used in clinical encounters and to support humor as a tool used to discuss difficult topics and bring warmth into the medical encounter.

To see this article online, please go to: http://jabfm.org/content/ 31/2/270.full.

\section{References}

1. Stewart MA. Effective physician-patient communication and health outcomes: A review. CMAJ 1995; 152:1423-33.

2. Ha JF, Longnecker N. Doctor-patient communication: A review. Ochsner J 2010;10:38-43.

3. Delzell JE Jr, Ringdahl EN, Kruse RL. The ACGME core competencies: A national survey of family medicine program directors. Fam Med 2005; 37:576-80.

4. Cousins N. Anatomy of an illness as perceived by the patient. New York, NY: W.W. Norton Company; 1979.

5. Goldstein JH, ed. Therapeutic effects of laughter. Sarasota, FL: Professional Resource Exchange, Inc; 1987.

6. Wender RC. Humor in medicine. Prim Care 1996; 23:141-54.

7. Francis L, Monahan K, Berger C. A laughing matter? The uses of humor in medical interactions. Motivation Emotion 1999;23:155-74.

8. Pawlikowska T, Zhang W, Griffiths F, van Dalen J, van der Vleuten C. Verbal and non-verbal behavior of doctors and patients in primary care consultations-How this relates to patient enablement. $\mathrm{Pa}-$ tient Educ Couns 2012;86:70-6.

9. Sala F, Krupat E, Roter D. Satisfaction and the use of humor by physicians and patients. Psychol Health 2002;17:269-80.

10. Levinson W, Roter DL, Mullooly JP, Dull VT, Frankel RM. The relationship with malpractice claims among primary care physicians and surgeons. JAMA 199719;277:553-9. 
11. Greene MG, Adelman RD, Friedmann E, Charon R. Older patient satisfaction with communication during an initial medical encounter. Soc Sci Med 1994; 38:1279-88.

12. McCarthy DM, Buckley BA, Engel KG, Forth VE, Adams JG, Cameron KA. Understanding patientprovider conversations: What are we talking about? Acad Emerg Med 2013;20(5):441-8.

13. Haskard Zolnierek KB, DiMatteo MR, Mondala MM, Zhang Z, Martin LR, Messiha AH. Development and validation of the Physician-Patient Humor Rating Scale. J Health Psychol 2009;14:1163-73.

14. Weber H, Stöckli M, Nübling M, Langewitz WA. Communication during ward rounds in internal medicine. An analysis of patient-nurse-physician interactions using RIAS. Patient Educ Couns 2007;67: 343-8.

15. Adamle KN, Ludwick R. Humor in hospice care: Who, where, and how much? Am J Hosp Palliat Care 2005;22:287-90.

16. Roter DL, Geller G, Bernhardt BA, Larson SM, Doksum T. Effects of obstetrician gender on communication and patient satisfaction. Obstet Gynecol 1999;93(5 Pt 1):635-41.

17. Shah ND, Mullan RJ, Breslin M, Yawn BP, Ting $\mathrm{HH}$, Montori VM. Translating comparative effectiveness into practice: The case of diabetes medications. Med Care 2010;48:S153-8.

18. Montori VM, Shah ND, Pencille LJ, et al. Use of a decision aid to improve treatment decisions in osteoporosis: The osteoporosis choice randomized trial. Am J Med 2011;124:549-56.

19. Mann DM, Ponieman D, Montori VM, Arciniega J, McGinn T. The Statin Choice decision aid in primary care: A randomized trial. Patient Educ Couns 2010;80:138-40.

20. LeBlanc A, Wang AT, Wyatt K, et al. Encounter Decision Aid vs. Clinical Decision Support or Usual
Care to Support Patient-Centered Treatment Decisions in Osteoporosis: The Osteoporosis Choice Randomized Trial II. PLoS One 2015;10(5): e0128063.

21. LeBlanc A, Herrin J, Williams MD, et al. Shared Decision Making for Antidepressants in Primary Care: A Cluster Randomized Trial. JAMA Intern Med 2015;175:1761-70.

22. Mullan RJ, Montori VM, Shah ND, et al. The diabetes mellitus medication choice decision aid: A randomized trial. Archives of Internal Medicine 2009; 169:1560-8.

23. Brito JP, Castaneda-Guarderas A, Gionfriddo MR, et al. Development and Pilot Testing of an Encounter Tool for Shared Decision Making About the Treatment of Graves' Disease. Thyroid 2015;25: 1191-8.

24. Stata Statistical Software: Release 14. College Station, TX: StataCorp LP; 2015.

25. Noldus. The Observer XT. In: Noldus.

26. Harris PA, Taylor R, Thielke R, Payne J, Gonzalez N, Conde JG. Research electronic data capture (REDCap)—A metadata-driven methodology and workflow process for providing translational research informatics support. J Biomed Inform 2009; 42:377-81.

27. Kreft IG, Kreft I, de Leeuw J. Introducing multilevel modeling. London, UK: SAGE Publications; 1998.

28. Institute S. JMP. Cary, NC: SAS Institute, Inc; 1989-2007.

29. Quill TE. Recognizing and adjusting to barriers in doctor-patient communication. Ann Intern Med 1989;111:51-7.

30. Flores G. Culture and the patient-physician relationship: Achieving cultural competency in health care. J Pediatr 2000;136:14-23. 